\title{
Fire disturbance disrupts an acacia ant-plant mutualism in favor of a subordinate ant species
}

Article in Ecology · March 2017

DOI: $10.1002 /$ ecy.1797

6 authors, including:

SEE PROFILE

SEE PROFILE

Kari E. Veblen

Utah State University

64 PUBLICATIONS 604 CITATIONS

University of Wyoming

SEE PROFILE

54 PUBLICATIONS $\mathbf{1 , 1 7 6}$ CITATIONS

SEE PROFILE

Some of the authors of this publication are also working on these related projects:

Conifer regeneration contingent on interacting abiotic and biotic factors View project

Summer water manipulation to flush weeds in restored grasslands View project 


\title{
Fire disturbance disrupts an acacia ant-plant mutualism in favor of a subordinate ant species
}

\author{
Ryan L. Sensenig, ${ }^{1,2,9}$ Duncan K. Kimuyu, ${ }^{2,3}$ Juan C. Ruiz Guajardo, ${ }^{2,4}$ Kari E. Veblen, ${ }^{2,5}$ \\ Corinna Riginos, ${ }^{2,6,7}$ and Truman P. Young ${ }^{2,8}$ \\ ${ }^{1}$ Department of Biological Sciences, Goshen College, Goshen, Indiana 46526 USA \\ ${ }^{2}$ Mpala Research Centre, P.O. Box 555, Nanyuki, Kenya \\ ${ }^{3}$ School of Natural Resource Management and Environmental Studies, Karatina University, Karatina, Kenya \\ ${ }^{4}$ Department of Evolution and Ecology and Center for Population Biology, University of California, Davis, California 95616 USA \\ ${ }^{5}$ Department of Wildland Resources and Ecology Center, Utah State University, Logan, Utah 84322 USA \\ ${ }^{6}$ Northern Rockies Conservation Cooperative, Jackson, Wyoming 83001 USA \\ ${ }^{7}$ Department of Zoology and Physiology, University of Wyoming, Laramie, Wyoming 82071 USA \\ ${ }^{8}$ Department of Plant Sciences, University of California, Davis, California 95616 USA
}

\begin{abstract}
Although disturbance theory has been recognized as a useful framework in examining the stability of ant-plant mutualisms, very few studies have examined the effects of fire disturbance on these mutualisms. In myrmecophyte-dominated savannas, fire and herbivory are key drivers that could influence ant-plant mutualisms by causing complete colony mortality and/or decreasing colony size, which potentially could alter dominance hierarchies if subordinate species are more fire resilient. We used a large-scale, replicated fire experiment to examine long-term effects of fire on acacia-ant community composition. To determine if fire shifted ant occupancy from a competitive dominant to a subordinate ant species, we surveyed the acacia-ant community in 6-7 yr old burn sites and examined how the spatial scale of these burns influenced ant community responses. We then used two short-term fire experiments to explore possible mechanisms for the shifts in community patterns observed. Because survival of ant colonies is largely dependent on their ability to detect and escape an approaching fire, we first tested the evacuation response of all four ant species when exposed to smoke (fire signal). Then to better understand how fire and its interaction with large mammal herbivory affect the density of ants per tree, we quantified ant worker density in small prescribed burns within herbivore exclusion plots. We found clear evidence suggesting that fire disturbance favored the subordinate ant Crematogaster nigriceps more than the dominant and strong mutualist ant C. mimosae, whereby C. nigriceps (1) was the only species to occupy a greater proportion of trees in 6-7 yr old burn sites compared to unburned sites, (2) had higher burn/unburn tree ratios with increasing burn size, and (3) evacuated significantly faster than $C$. mimosae in the presence of smoke. Fire and herbivory had opposite effects on ant density per meter of branch for both $C$. nigriceps and C. mimosae, with fire decreasing ant densities per meter of branch and the presence of large herbivores increasing ant density. Taken together, these experiments suggest that major ecosystem disturbances like fire can disrupt mutualistic associations and maintain diversity in partner quality and identity despite a clear dominance hierarchy.
\end{abstract}

Key words: Acacia drepanolobium; browsing; Crematogaster; disturbance; fire-herbivore interactions; grain; Kenya; Laikipia; spatial scale.

\section{INTRODUCTION}

Mutualisms play an important role in maintaining terrestrial biodiversity and ecosystem functioning (Wardle et al. 2004, Klein et al. 2007, Estes et al. 2011). Antplant mutualisms, in particular, can significantly shape community ecological interactions in tropical systems (Bronstein 2015). The strength and long term stability of these associations, however, depends upon the level of investment placed by each mutualistic partner and the

Manuscript received 15 August 2016; revised 7 February 2017; accepted 24 February 2017. Corresponding Editor: Peter K. Kotanen.

${ }^{9}$ E-mail: rlsensenig@goshen.edu local environmental disturbances (Bronstein 1998, González-Teuber et al. 2012), which may impact these interactions via weather perturbations (e.g., Piovia-Scott 2011), resource limitation (e.g., Pringle et al. 2013), and herbivory (e.g., Pringle et al. 2012). Although ecological disturbance theory has been recognized as a useful framework in examining the stability of ant-plant mutualisms (Arnan et al. 2013) very few studies have examined the effects of fire on these mutualisms (but see Kimuyu et al. 2014, Pires and Del-Claro 2014).

In myrmecophyte-dominated savannas fire and herbivory are key disturbances that structure plant communities (Fuhlendorf and Engle 2004, Kerby et al. 2007, de Dantas et al. 2016) and regulate tree:grass ratios (Sankaran et al. 2008, Asner et al. 2009, Trollope 2011). 
In these ecosystems, ant-plant mutualisms serve important roles with cascading impacts on species assemblages (Schumer et al. 2013), canopy insect communities (e.g., Kuria and Villet 2012), tree-grass competition, and resource heterogeneity (e.g., Goheen and Palmer 2010). Given the importance of ant-plant mutualisms, the effects of fire-induced ant mortality are of growing interest among ecologists (Palmer et al. 2008b, Caut et al. 2014, Kimuyu et al. 2014). In these systems, there is widespread evidence of elaborate evolutionary responses of native plants and animals to fire (e.g., Sankaran et al. 2008, Levick et al. 2009, Sensenig et al. 2010, Pringle et al. 2015). However, we lack an understanding regarding the mechanisms by which ants tolerate fire, how traits related to fire adaptation may influence long term ant community composition, and whether the scale and/ or intensity of the disturbance influences these responses.

Insects may respond to fire disturbance with "survivor" traits, such as when butterflies bury pupae beneath soil duff (Thom et al. 2015) or when ants evacuate with their brood into cracks in the soil beneath host trees (Palmer et al. 2008a, Jaffe and Isbell 2009). Alternatively, ant communities may exhibit classic competition-colonization trade-offs whereby subordinate species may respond to fire by adopting a "colonist" strategy through claiming vacant host plants once the fire disturbance has passed (Stanton et al. 2002).

It is increasingly understood that spatial patterns of heterogeneity influence species coexistence (e.g., Stein et al. 2014). For example, in savannas, it is clear that fire-induced heterogeneity creates landscape patterns that influence large herbivore foraging (Sensenig et al. 2010), movement (Kerby et al. 2007) and perhaps even coexistence (Cromsigt and Olff 2006), but in myrmecophyte-dominated savannas, persistence of ant species in the context of landscape heterogeneity created by fire has not been examined. Ant survival depends on either evacuating from host trees prior to an approaching fire (New 2014) and/or recolonization of the burned patches after the disturbance has passed (Stanton et al. 2002), both of which could be influenced by fire grain or extent. For example, larger, coarse-grained burns in contrast to smaller, fine-grained burns, often have higher temperatures, faster rates of spread, and create post-burn habitat with less edge, scenarios that may affect both ant survival and recolonization patterns (Verble-Pearsons and Yanoviak 2014).

In savannas fire also interacts with herbivory (e.g., Fuhlendorf and Engle 2004, Collins and Smith 2006) in ways that may have important consequences for antplant mutualisms. Whereas mammalian herbivore presence reinforces ant-plant mutualistic interactions (Palmer et al. $2008 a$ ), we lack an understanding of how herbivory and fire together influence these mutualisms. There is growing evidence that megaherbivores (mainly elephants) and fire exert synergistic effects in reducing tree densities (Okello et al. 2008, Holdo et al. 2009, Staver et al. 2009, Shannon et al. 2011). For example burning may indirectly increase megaherbivore browsing by increasing mortality of symbiotic ants, thereby reducing the defensive efficacy of the ant-plant mutualism. However, there are virtually no studies that simultaneously manipulate the combined effects of fire and herbivory to study their ecological impacts on ant mutualist densities.

We used a large-scale, replicated fire experiment to examine long term effects of fire on the community composition of a symbiotic ant guild inhabiting the whistling-thorn Acacia (Vachellia) drepanolobium. To evaluate potential shifts in ant composition on $A$. drepanolobium across the landscape at longer timescales (6-7 yr after burning), we quantified how the relative abundance of each ant species changed in response to fire, and examined if the spatial scale of fire disturbances influenced these dynamics. We followed this experiment with two short-term fire studies to explore possible mechanisms for the shifts in community patterns we observed. First, we measured differences among the four ant species in colony evacuation response to smoke. Second, we examined how fire and the controlled presence or absence of large mammalian herbivores influenced ant density on individual trees after burning.

\section{Study Site And Methods}

\section{Study site and system}

This research was carried out at Mpala Research Centre and adjacent properties in the Laikipia Plateau, Kenya (36 $52^{\prime}$ E, $0^{\circ} 17^{\prime} \mathrm{N} ; 1810 \mathrm{~m}$ above sea level) where rainfall averages $550-600 \mathrm{~mm}$, and is weakly tri-modal, with a distinct dry season December-March. The area is underlain by "black cotton" vertisol soils, where woody vegetation is dominated by Acacia drepanolobium (>98\%; Young et al. 1997). In this system, four mutually exclusive symbiotic ant species (Crematogaster sjostedti, C. mimosae, C. nigriceps, Tetraponera penzigi) compete intensively for host trees, with the outcomes of aggressive confrontations determined by colony size, ant density, and aggression (Palmer et al. 2000, Ruiz Guajardo et al. 2017). These four ants defend their host trees against herbivory in exchange for housing and food (Madden and Young 1992), although the different fitness benefits of each ant species for the host trees is complex (Stanton et al. 1999, Palmer et al. 2008b, 2010, Stanton and Palmer 2011). The relative abundances and frequencies changing across the landscape in relation to community structure, tree ontogeny, tree production, and browser regimes (Young et al. 1997, Palmer et al. 2010, Quintero et al. 2013). Saplings and small trees are colonized both by colony expansion from any of the Crematogaster species, but also by new colonies of $T$. penzigi, and secondarily by $C$. nigriceps. Among intermediate trees $(<5 \mathrm{~m})$ the two most common species are $C$. mimosae and $C$. nigriceps, with all species usually replaced by $C$. sjostedt $i$ in the oldest trees (Young et al. 1997). Subordinate ant species (e.g., C. nigriceps) resort to biological strategies 
(including tree pruning) to decrease interspecific competition and increase colony survivorship (Stanton et al. 1999, Palmer et al. 2002, Palmer 2004).

Common grass species growing in the "black cotton" vertisol soils include Pennisetum stramineum, P. mezianum, Themeda triandra, Brachiaria lachnantha, and Lintonia nutans (Young et al. 1997), which form a dense continuous layer of fuel making the system highly susceptible to fire. In this system, there is widespread evidence of elaborate evolutionary responses of native plants and animals to fire (e.g., Levick et al. 2009, Sensenig et al. 2010). Although the application of fire as a management tool was common in the 1960s (Heady 1960), fire has not been frequently applied in the last four decades. Large mammalian browsers (and mixed feeders) in this system include elephant (Loxodonta africana), giraffe (Giraffa camelopardalis), Grant's gazelle (Nanger [Gazella] granti), and eland (Taurotragus oryx).

\section{Long term shifts in ant species composition following burning: SAFE burn experiment}

To test whether fire differentially affects ant residency at longer time scales and different spatial scales, we resurveyed large scale burn plots burned in 2004 and 2005 as part of the SAFE (scale and fire ecology) project (Sensenig et al. 2010). The SAFE experimental burns vary in their grain size $(30,100,300$, and $900 \mathrm{~m})$, spatial pattern (two levels: continuous and patchy), and extent (1, 9, and 81 ha) as depicted in Fig. 1. Continuous burns offered a complete burn without unburned refuges, and patchy burns utilized fire-breaks to create unburned refuges among smaller burned patches. The variation in grain size makes the experimental design ideally suited to explore how burn grain influences post-burn ant community dynamics. All burns were implemented at the end of the dry season in February/March of 2004 and 2005

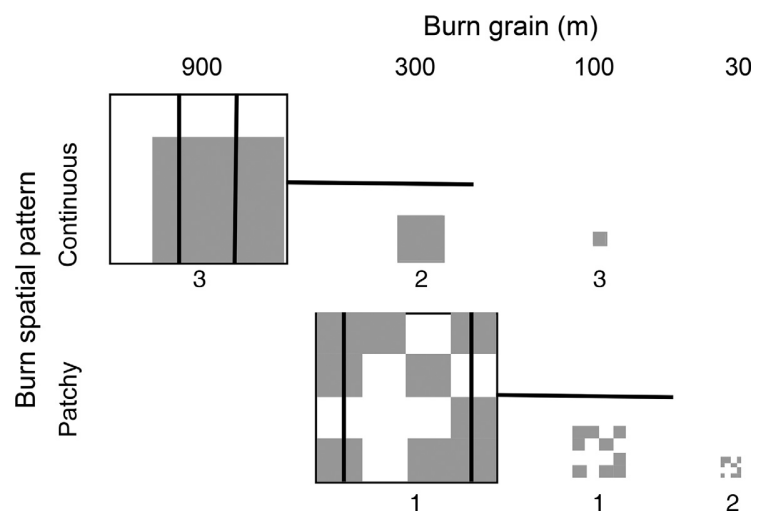

FIG. 1. The SAFE (scale and fire ecology) experimental design in which burns varied in their spatial pattern (patchy vs. continuous) and grain size (30, 100, 300, and 900 m). Heavy lines (only shown for largest burns) indicate locations of $10 \mathrm{~m}$ wide belt transects used to quantify tree attributes in burned (shaded) and unburned areas (white). Numbers indicate number of replicates. before the long rains. All understory above-ground grass vegetation was removed by burning and, although trees $<1 \mathrm{~m}$ tall were often top-killed by the burns, taller trees $(>2 \mathrm{~m})$ suffered only superficial damage (singed leaves). For the 2005 burns, we monitored fire temperatures with ceramic tiles painted with Tempilaq paints (LA-CO Industries, Elk Grove, Illinois, USA) (see Sensenig et al. 2010 for full details).

In June-July of 2011, we surveyed the 12 of 18 SAFE plots that had not been further modified (i.e., accidental re-burning, or placement of cattle corrals in the plots). In each burned plot, we established $10 \mathrm{~m}$ wide belt transect that bisected the entire burn and continued into the unburned matrix to a distance equivalent to the length of the burn treatment. As a result, the areas surveyed in burned and unburned sections were similar for each burn size (Fig. 1). Along each belt transect, we counted all individuals of $A$. drepanolobium $(n=13,000)$ and measured their height and stem diameter at $15 \mathrm{~cm}$, recorded the presence/absence of swollen thorns, and identified the ant species living on the tree. We standardized counts by calculating the tree densities (trees/ha) for each ant species in both burned and unburned areas (see Appendix S1: Table S1 for data on total trees counted per plot). For each ant species, we used these data to calculate a burn/unburn tree ratio for each plot by dividing the mean number of trees per hectare in the burned areas by the mean number of trees per hectare in the adjacent unburned areas.

\section{Ant evacuation behavior in response to smoke}

In May of 2014, to better understand mechanisms that might drive ant community shifts in response to burning, we quantified fire-induced evacuation behaviors of the four ant species that reside in A. drepanolobium trees by testing responses to smoke in two separate "smoke transects." For each experiment, we burned elephant dung and dried grass in a 3 -gallon $(1$ gallon $=3.8 \mathrm{~L})$ metal bucket to create a small, sustained, smoke source for the duration of $1 \mathrm{~h}$. In the first experiment, we placed two observers every $50 \mathrm{~m}$ along a $500-\mathrm{m}$ transect downwind from the smoke source. At each distance, we selected the nearest four trees each occupied by a different ant species (when available): Crematogaster mimosae, C. nigriceps, C. sjostedti, or Tetraponera penzigi. At each distance, two observers quantified evacuation rates by counting the number of ants moving down the main trunk past a point $1 \mathrm{~m}$ off the ground. Ants were considered evacuating only if they were moving down the trunk (see Video S1). Ants were counted for $30 \mathrm{~s}$ of each minute for the duration of burning. In a second $1.8-\mathrm{km}$ transect, we repeated the experiment for the two most common species (C. $m i$ mosae and $C$. nigriceps) to determine how ants responded at greater distances. Using the same counting protocol as in the shorter transect, two different observers were placed at 200-m intervals from the smoke source and four trees were selected for analysis (two trees occupied by C. mimosae and two occupied by $C$. nigriceps). In the 
second transect, we also controlled for potential differences in ant densities per tree by estimating the ant density per branch for each tree. After ants returned to their trees (approximately $1 \mathrm{~h}$ after the smoke experiment) we clipped three swollen thorns from a randomly selected branch, capturing ants inside the thorn by plugging their entrance holes. Thorns were opened in the lab, all adult workers counted, and the total worker density per branch estimated by multiplying the mean density per thorn by the number of thorns per branch. Both smoke evacuation experiments were conducted before the long rains when grass fuel loads were dry.

\section{Short-term ant density response to burning and herbivory: KLEE burn experiment}

To examine short-term effects of fire on ant densities with and without large herbivores, we made use of the Kenya Long-term Exclosure Experiment (KLEE). The KLEE has been manipulating the presence and absence of three guilds of large herbivores since 1995 using $200 \times 200 \mathrm{~m}$ plots that use semipermeable barriers to exclude different combinations of livestock (cattle), wild mesoherbivores (large mammals 20-1000 kg), and megaherbivores (elephants and giraffes; Young et al. 1997). Depending on the herbivore species that are excluded in each plot, there are six treatments, each replicated three times in a randomized block design (see Young et al. 1998 for full details).

In late February 2013, we burned $1830 \times 30 \mathrm{~m}$ subplots, one in each of the 18 4-ha KLEE plots. The interiors of all plots were burned using head-fires and all burns consumed virtually all of the aboveground understory vegetation (except for tussock bases) and fine woody debris (for more details, see Kimuyu et al. 2014). We resampled the KLEE burn subplots and their adjacent unburned areas approximately 4, 16, and 40 months after burning. Plots accessible to elephants, giraffe, and mesoherbivores (but not cattle) were grouped together as "large herbivores present" and plots accessible to cattle only or completely fenced were grouped together as "large herbivores excluded" for a total of six burned plots and six unburned plots in each herbivore treatment. To understand how burning affects the relative ant density per tree for the two most common ant species, in each burned and unburned plot (a total of 24 plots), we randomly selected three 1-3 $\mathrm{m}$ tall trees occupied by $C$. mimosae and three trees occupied by $C$. nigriceps and estimated ant density as the number of ants per meter of branch. In June-August of 2013 ( 4 months after burning), we sampled thorns from 77 trees. Due to shifts in ant species occupancy, tree mortality, or loss of tree tags due to wildlife, we increased sample size in May-June of 2014 ( $\sim 16$ months after burning) by adding new trees not previously sampled for a total of 157 trees. In June of 2016 ( 40 months after burning) we resampled 103 trees.

On each selected tree, we randomly chose a $1-2 \mathrm{~cm}$ diameter branch from the main trunk, measured its cumulative length inclusive of all twigs, and counted the total number of swollen thorns. From the same branch or nearby branches, we randomly selected three to four old lignified swollen thorns and, if present, three to four new un-lignified swollen thorns. We plugged the ant entrance holes with thorns and tape to prevent the ants from escaping, removed the swollen thorns, and placed them in a $-40^{\circ} \mathrm{C}$ freezer for $\sim 2 \mathrm{~h}$ to immobilize the ants for counting. Thorns were cut open and all adult workers were counted separately for each thorn. To obtain ant densities per meter of branch, we multiplied the mean number of workers per swollen thorn by the number of thorns on the branch and divided this value by the cumulative length of the branch.

\section{Statistical analysis}

SAFE large-scale burns. - For each plot, we calculated the number of trees per hectare occupied by each ant species for both burned and unburned sections of the belt transect. To determine if the proportion of trees occupied by each ant species was influenced by burning, we used two-tailed $t$ tests to determine if the proportion of trees occupied by each ant differed in burned and unburned areas, with all plots averaged together irrespective of burn grain size. We also created a burned/unburned tree ratio for each ant species by dividing the absolute number of trees per hectare in the burned area by the absolute number of trees per hectare in the neighboring unburned area separately for each plot. To assess whether the burn spatial attributes influenced ant responses to fire, we used multiple regression with the mean burned/unburned tree ratio as the response variable and grain size, ant species, and the interaction between ant species and grain size as the explanatory variables. Plots were assigned a grain size of $30,100,300$, or $900 \mathrm{~m}$ based on the size of the burned patches that comprise the treatment (Fig. 1; Appendix S1: Table S1). For example, "1-ha patchy" burns contain a grain size of $30 \mathrm{~m}$, while both " 1 -ha continuous" and "9-ha patchy burns" contain a grain size of $100 \mathrm{~m}$. We performed an additional multiple regression analysis to test whether variability in burn temperatures influenced tree ratios (given that temperature may be correlated to burn spatial attributes). For this analysis, we only included 2005 burns (burn temperatures were not measured for 2004 burns) with burned/unburned tree ratio as the response variable and grain size, ant species, the interaction between ant species and grain size, and the mean burn temperature as explanatory variables. To meet assumptions of normality of residuals we applied a Box-Cox transformation to the response variable for both regression models.

Ant evacuation behavior.-We used the 500-m smoke transect data to determine which of the four ant species responded to smoke. Given the lower abundance of $\mathrm{Cre}$ matogaster sjostedti and Tetraponera penzigi across the landscape, we were limited to finding three trees for each 
of those species directly in line with our smoke transect. We used one-way ANOVA with Tukey's HSD (which is conservative for unequal sample sizes) to determine if mean ants evacuating per $30 \mathrm{~s}$ differed by species. To meet assumptions of normality of residuals we log-transformed $\left(y^{\prime}=\log [y+1]\right)$ the response variable.

To analyze data from the $1800-\mathrm{m}$ smoke transect, for both $C$. mimosae and $C$. nigriceps at each distance, we calculated the following metrics per tree: (1) maximum ant evacuation per $30 \mathrm{~s}$ and (2) mean time to maximum evacuation, defined as the time elapsed from the start of the fire until maximum evacuation rates were reached. The first metric allowed us to determine if one species was more efficient at evacuating, and the second metric assessed whether a species initiated evacuation sooner. Replicates of each species of ants were averaged at each distance and we used two separate ANCOVAs to determine if the mean maximum ant evacuation and the mean time to maximum evacuation differed by ant species with distance from the smoke as a covariate. To ensure that differences in ant evacuation metrics were not simply due to differences in initial densities on the tree, we used one-way ANOVA to determine if initial ant densities differed by ant species.

KLEE burns. - In each burned and unburned subplot, we combined data from all trees to create plot means separately for 2013, 2014, and 2016 for just the two most abundant ant species, $C$. nigriceps and $C$. mimosae. To test whether fire and the presence of large herbivores affected the total ant worker density per meter of branch, we used a split-plot analysis with plot nested within herbivore/no large herbivore treatment with the following fixed factors: year, burned/unburned, large herbivore/no large herbivore, ant species (C. nigriceps and C. mimosae), and their potential interactions. Plot nested within large herbivore/no large herbivore was included as a random effect. We excluded trees on which ant colony takeovers occurred (one tree was thus excluded between 2013 and 2014 and 10 trees were excluded between 2014 and 2016). We also excluded from these models $C$. sjostedti because it mainly resides in stem cavities and not in swollen thorns, and Tetraponera penzigi because of low sample sizes. To achieve normality of residuals, we tested for outliers using Mahalanobis distances for each point from the multivariate mean. Three under-sampled subplots were excluded as outliers (representing four trees). We present $P$-values for analysis with and without outliers. All analyses were completed with JMP 10.0.2 (SAS Institute Inc., Cary, North Carolina, USA).

\section{RESULTS}

\section{Long-term ant compositional shifts in response to burning at multiple scales: SAFE burns}

In 2011, seven years after the SAFE burns (Fig. 1) were implemented, ant community composition was significantly different between burned and unburned areas, with shifts toward the subordinate $C$. nigriceps, the only species to occupy a higher proportion of trees in burned plots (147\% increase) compared to neighboring unburned areas $\left(F_{1,47}=2.26 ; P=0.029\right.$, Fig. 2$)$. The proportion of trees occupied by the other three ant species all declined in burned sites relative to unburned sites (C. mimosae $92 \%$, C. sjostedti $78 \%$, and T. penzigi $63 \%$ ), with the latter two species declining most significantly (Fig. 2). Similarly, we found differences in burned/unburned tree ratios among the four ant species $\left(F_{3,39}=5.2, P=0.0041\right)$ and $C$. nigriceps had a higher ratio of trees in burned areas than $C$. mimosae $\left(F_{1,39}=4.7, P=0.036\right)$. The main effect of grain size on tree ratios was not significant $\left(F_{1,39}=0.24\right.$, $P=0.63)$, though there was a significant interaction between ant species and grain size $\left(F_{3,39}=3.13\right.$, $P=0.037$; Fig. 3). Crematogaster nigriceps was the only species for which tree burned/unburned ratios increased with increasing grain size (see Appendix S1: Table S2, $P=0.032$ ). We did not find an effect of temperature on burned/unburned ratios $\left(F_{1,23}=0.21, P=0.65\right)$ and the inclusion of temperature in the analysis (for just the 2005 burns) did not alter the patterns related to $C$. nigriceps (see Appendix S1: Table S2). The density of trees per hectare was on average $6 \%$ higher in unburned areas, with shifts in height classes toward shorter trees in burned areas due to coppicing of top-killed trees (see Appendix S1: Fig. S2).

\section{Ant evacuation behavior in response to smoke}

In the first smoke transect, we found dramatic differences in how the four ant species responded to smoke. Two species, $C$. sjostedti and $T$. penzigi, did not evacuate from trees, while both $C$. nigriceps and $C$. mimosae evacuated readily (Fig. 4). In the $1.8-\mathrm{km}$ smoke transect, both $C$. nigriceps and $C$. mimosae were highly sensitive to very small amounts of smoke, evacuating up to

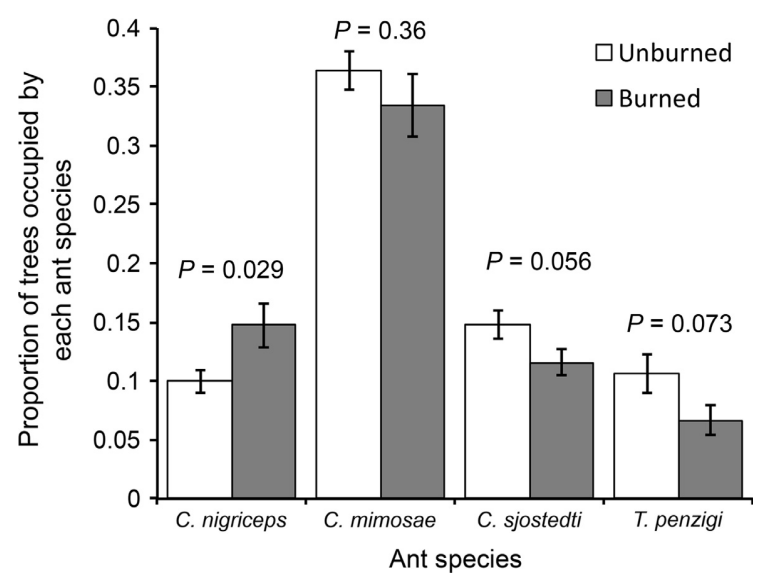

FIG. 2. Proportion of all trees (mean \pm SE) occupied by each ant species across all SAFE burn plots in both burned (shaded) and unburned plots (white). Probability values indicate if differences were found between burned and unburned proportions for each ant species using simple $t$ tests. Ant genera are Crematogaster and Tetraponera. 


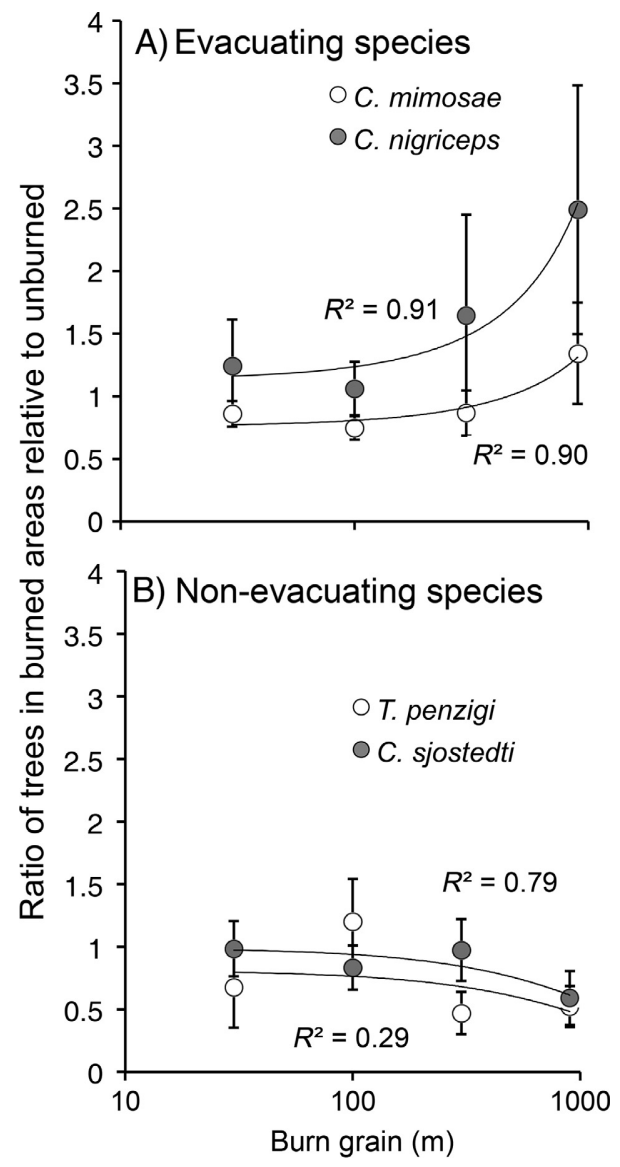

FIG. 3. Burn/unburn ratios (mean $\pm \mathrm{SE}$ ) in SAFE burns for (A) evacuating species and (B) non-evacuating species as a function of $\log$ (burn grain size). Crematogaster nigriceps was the only species for which tree burn/unburn ratios increased with increasing grain size (Appendix S1: Table $\mathrm{S} 2, P=0.032$ ).

$1,800 \mathrm{~m}$ from the smoke source (see the recording of ant evacuation: Video S1). However, the subordinate C. nigriceps evacuated twice as quickly as C. mimosae $\left(F_{1,15}=6.85, P=0.0009 ;\right.$ Fig. 5$)$. Although $C$. nigriceps evacuated sooner, we did not find differences between $C$. nigriceps and $C$. mimosae in the maximum number of ants moving off the trees per $30 \mathrm{~s} \quad\left(F_{1,15}=0.012\right.$, $P=0.91$; see Appendix S1: Fig. S1) and there were no differences in initial ant densities between the two ant species $\left(F_{1,25}=0.043, P=0.83\right)$.

\section{Ant density responses to burning and large mammalian herbivores: KLEE burns}

Both burning and the presence of large herbivores significantly affected ant densities per meter of branch, though in opposite directions (Fig. 6, see Appendix S1: Table S3). Burned trees had 59\% fewer ants per meter of branch than unburned trees $\left(F_{1112}=17.25, P=0.0004\right)$. Trees in plots accessible to large herbivores had higher ant densities than trees in exclusion plots, which harbored

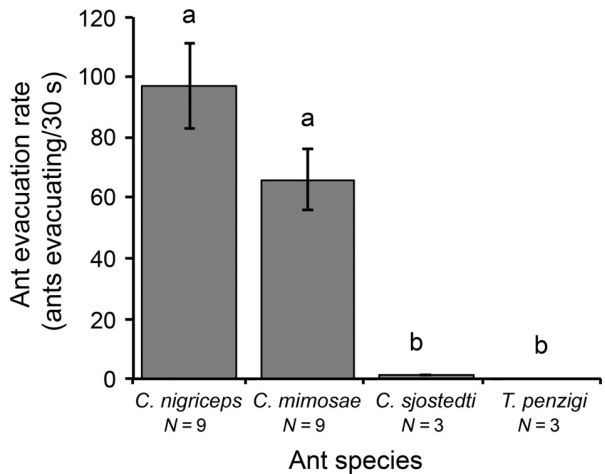

FIG. 4. Number of ants evacuating per $30 \mathrm{~s}$ (mean \pm SE) in response to smoke along a 500-m smoke transect for all four ant species. The variable $n$ is the number of trees included in each mean; letters indicate significant differences using Tukey's HSD.

$39 \%$ fewer ants per meter of branch $\left(F_{1,112}=15.1\right.$, $P=0.0009)$. We found a significant interaction between burning and herbivory $\left(F_{1,112}=7.1, P=0.015\right)$, with burning exerting a more substantial reduction in ant densities in trees accessible to herbivores than in trees where herbivores were excluded (Fig. 6). We found no difference between $C$. mimosae and $C$. nigriceps in their ant densities per meter of branch $\left(F_{1,112}=0.61, P=0.44\right)$. We did not find an interaction between ant species and burning, indicating C. nigriceps and C. mimosae ant densities per meter of branch were impacted in similar ways by fire (at least at this burn spatial scale, $F_{1,112}=0.34, P=0.56$ ), nor was there a three-way interaction between species, burning, and herbivory $\left(F_{1,112}=0.00003, P=0.996\right)$. We found a significant interaction between survey year and burning $\left(F_{2,112}=10.6, P<0.0001\right)$, with ant densities increasing through time in burned plots and decreasing through time in unburned plots. The removal of outliers improved the normality of residuals and had no effect on significance values with the exception of the interaction between burning and herbivory (Appendix S1: Table S3), which became marginally significant when outliers were not excluded $\left(F_{1,115}=4.1, P=0.053\right)$.

\section{Discussion}

Previous work has demonstrated that $C$. mimosae is one of the most abundant species across large areas of our study site (which is rarely burned) and is competitively dominant over $C$. nigriceps (Palmer 2004). We previously demonstrated that a single dry season fire significantly reduced survival of symbiotic ants living on A. drepanolobium trees (Kimuyu et al. 2014). In that study, we found the percentage of trees on which ants survived after burning was highest for the subordinate ant species C. nigriceps (82-91\%, depending on height class) and lower for the other species: C. mimosae (68-75\%), C. sjostedti (37-68\%), and T. penzigi (5-13\%).

In this paper, we provide additional long-term and short-term evidence that fire disturbance shifts ant 


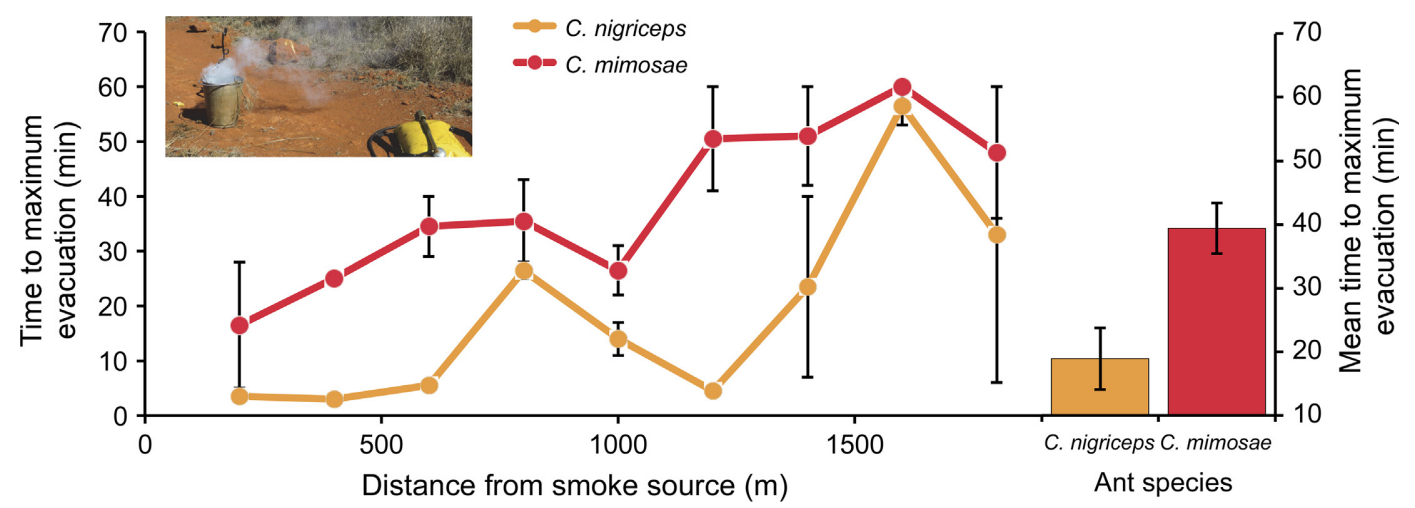

FIG. 5. Elapsed time to maximum evacuation (mean $\pm \mathrm{SE}$ ) for Crematogaster mimosae (darker/red circles) and $C$. nigriceps (lighter/orange circles) ant colonies along an 1,800-m smoke transect. Column means in the bar chart represent averages ( \pm SE) of all distances together. [Color figure can be viewed at wileyonlinelibrary.com]

community structure toward favoring the subordinate ant species (C. nigriceps). The proportion of trees occupied by Crematogaster nigriceps was higher in burned areas 6-7 yr after burning at the expense of all three

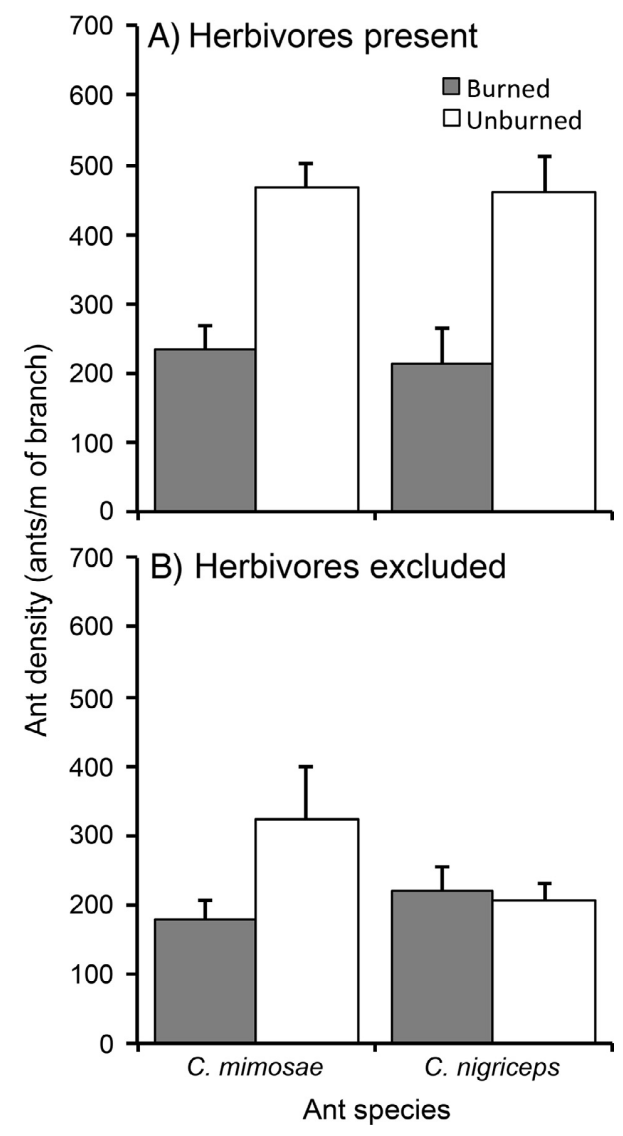

FIG. 6. Number of ants (Crematogaster mimosae and C. nigriceps) per meter of branch (mean $+\mathrm{SE}$ ) in burned (shaded) and unburned (white) subplots in KLEE treatments that are (A) accessible to large herbivores and (B) treatments where large herbivores were excluded. The species interaction with herbivory and fire was not statistically significant (Appendix S1: Table S3; $P=0.996$ ). other ant species (Fig. 2), C. nigriceps was the only species that significantly benefited from burns of larger grain size (Fig. 3), and C. nigriceps evacuated significantly sooner than the dominant competitor (C. mimosae) in the presence of smoke (Fig. 5). Taken together, these findings suggest that ant species are not all equally tolerant to fire disturbance, and that fire may be an overlooked factor helping to maintaining subordinate species $(C$. nigriceps $)$ in the context of a linear dominance hierarchy $(C$. mimosae $>C$. nigriceps $)$.

The patterns we noticed in the long-term SAFE study further suggest that burn spatial dynamics influence ant community ecology. Although our study does not elucidate the precise adaptations that improve the performance of $C$. nigriceps in burned landscapes, the findings from the smoke-transect experiments suggest that the rapid and early evacuation behavior of $C$. nigriceps relative to other species may be relevant in explaining (1) why a higher percentage of $C$. nigriceps colonies survived after fire (Kimuyu et al. 2014) and (2) why C. nigriceps ants performed better in large-grain burns (Fig. 3). If evacuation is important in subsequent survival and recolonization, ant colonies would receive more advance warning via smoke cues in larger burns than smaller burns, a situation that would advantage $C$. nigriceps given its ability to evacuate on average 20 minutes sooner than its strongest competitor.

Additionally, scale-related processes related to recolonization of abandoned trees from nearby colonies in unburned areas could also be primary drivers in influencing shifts to $C$. nigriceps. Stanton and Palmer (2011) reported a classic competition-colonization trade-off where the subordinate species (T. penzigi and C. nigriceps) are superior initial colonizers of the smallest trees than the competitive dominants $(C$. sjostedti and C. mimosae). In their study, they demonstrated that, when colonization happens through the arrival of new queens, both subordinates are better colonizers of coppicing trees from which ants were removed by disturbance (in their case, cutting trees to mimic elephants and fire). This is consistent with our findings from the SAFE 
burns where burns of smaller grain size (with high edge: area ratios) had less dramatic shifts to the subordinate C. nigriceps (Fig. 3). Vacated trees in burns of smaller grain size could potentially be more readily recolonized by aggressive colony takeovers by $C$. mimosae and/or C. sjostedti colonies outside the burn area. In contrast, C. nigriceps might also benefit from larger fires given that its flying queens are competitively superior to those of $C$. mimosae, enabling it to recolonize the interior of burns with larger grain size (Stanton et al. 2002). It is somewhat surprising that Tetraponera penzigi, a strong queen colonizer of shorter saplings, did not become more common in burned areas given we also noticed shifts to shorter tree height classes (due to coppicing by top-killed trees, see Appendix S1: Fig. S2). One explanation is that since T. penzigi colonies have the highest mortality from fire $(5-13 \%$ colony survival reported by Kimuyu et al. 2014), their ability to recolonize vacant trees could be severely compromised. Regardless of the underlying mechanisms (evacuation, recolonization, or both) our data emphasize the importance of considering the spatial scale of fire disturbances. These findings contribute to a growing appreciation for the complexity of insect adaptations to fire, which include the ability to sense smoke at great distances (Schütz et al. 1999) and fire-dependent life cycle and behavioral adaptions (LarsOve 1997). In this regard, our findings suggest that the spatial scales of fire disturbances deserve further consideration and may be fundamental to understanding insect community responses to fire.

Although a "fire-alarm" evacuation strategy confers some level of reprieve from direct fire mortality, a significant proportion of an evacuating colony may still succumb to fire. Although C. nigriceps and C. mimosae ant densities declined dramatically immediately after burning, differences in ant density per meter of branch between burned and unburned plots for both species disappeared after 3 yr. We expected that the more firetolerant species, C. nigriceps, would have higher ant densities after burning than C. mimosae, due to their tendency to evacuate sooner, but that is not what we found (Fig. 6). However, since the grain size of the KLEE burns is small $(30 \mathrm{~m})$, advantages in rapid evacuation and long-distance colonization by $C$. nigriceps were potentially diminished. Further research is required to establish whether there exist fire-induced differences in ant densities per tree between C. nigriceps and C. mimosae in burns of varying sizes.

The effect of large herbivores on ant density is consistent with other work demonstrating that browsing by megaherbivores increases host investment in swollen thorns and nectaries, which leads to higher worker production and aggression to defend higher quality resources (Palmer et al. 2008b, Stanton and Palmer 2011, Ruiz Guajardo et al. 2017). However, we found a significant interaction between herbivory and fire with burning reducing ant densities per meter of branch dramatically in herbivore-accessible plots but less so in herbivore exclusion plots (Fig. 6), suggesting the effects of fire on ant community dynamics is influenced by browsing history. It also suggests that, if these ecosystems lose their large mammalian herbivores (Dirzo et al. 2014), fire will tend to have an increasing role in structuring the ant communities.

Interestingly, the interaction between fire and browsing not only may influence ant densities on trees, subsequent changes in ant densities could influence future large herbivore visitation by browsers like elephants. Since previous work has demonstrated that complete removal of ants from $A$. drepanolobium trees leads to increased browsing pressure (Goheen and Palmer 2010, Stanton and Palmer 2011, Riginos et al. 2015), it is plausible that fire-induced punctuated reductions of ants may attract elephants (Pringle et al. 2015), emphasizing that fire-ant-browser interactions deserve special attention in understanding tree dynamics in myrmecophytedominated savannas.

More broadly, the mutualism literature has focused considerable attention on understanding the effects of disturbance on the integrity of mutualisms (e.g., Bond 1994, Christian 2001, Bronstein 2015), with many studies addressing how anthropogenic disturbances negatively influence seed dispersal and pollination mutualisms (Chapman and Chapman 2003, Gray et al. 2007, Rodríguez-Cabal et al. 2007). In contrast, sometimes anthropogenic activities reduce the impact and/or frequency of natural perturbations that are essential to maintaining mutualisms (Stachowicz 2001, Zelikova and Breed 2008, Keeley et al. 2012). Consistent with this view, our study suggests the effects of fire disturbance on mutualisms are likely to be site dependent and determined by frequency, spatial scale, and interspecific responses (e.g., competition vs. colonization) among mutualistic partners. An equally intriguing insight provided by this research is the identification of a novel disturbance mechanism that can disrupt mutualistic associations and maintain diversity in partner quality and identity despite a clear dominance hierarchy. This adds to a growing body of research exploring the role of environmental factors such as heterogeneity in abiotic factors, resource availability, and biotic pressures such as herbivory in explaining the persistence of sub-optimal partners in mutualistic associations. Taken together, these experiments suggest that species-specific responses to major ecosystem disturbances like fire effectively reorganize acacia ant communities, highlighting the importance of integrating fire ecology into our understanding of ant-plant mutualisms.

\section{AcKNOWLEDgments}

Thanks to T. M. Palmer, two anonymous reviewers, and reviews provided by Axios for helpful comments on the manuscript. Thanks to the following student researchers from Goshen College who assisted in field work: J. Davila, A. Fretz, W. Kanagy, J. Penner, C. Quick, P. Reimer, E. Schertz, L. Schlabach, D. Stoesz, J. Yoder, T. Yoder, and L. Zehr. Thanks also to the Goshen College Savanna Research class of 2014, whose 
members assisted in the smoke transects. We thank the fire crew team, especially F. Erii, J. Lochukuya, M. Namoni, J. Ekadeli, W. Longor, N. John, J. Ekiru, S. Lima, and B. Kirwa. Essential logistical support was provided by Mpala Farm (Michael Littlewood) and Mpala Research Centre (Margaret Kinnaird, Alick Roberts, and Julius Nakalonyo). The KLEE exclosure plots were built and maintained by grants from the James Smithson Fund of the Smithsonian Institution (to A. P. Smith), The National Geographic Society (Grants 4691-91 and 9106-12; to T. P. Young), and The National Science Foundation (LTREB BSR 97-07477, 03-16402, 08-16453, 12-56004, and 12-56034; to T. P. Young, K. E. Veblen, and C. Riginos). Additional funding support came from Goshen College (to R. L. Sensenig).

\section{Literature Cited}

Arnan, X., X. Cerdá, A. Rodrigo, and J. Retana. 2013. Response of ant functional composition to fire. Ecography 36:1182-1192.

Asner, G. P., S. R. Levick, T. Kennedy-Bowdoin, D. E. Knapp, R. Emerson, J. Jacobson, M. S. Colgan, and R. E. Martin. 2009. Large-scale impacts of herbivores on the structural diversity of African savannas. Proceedings of the National Academy of Science USA 106:4947-4952.

Bond, W. J. 1994. Do mutualisms matter - assessing the impact of pollinator and disperser disruption on plant extinction. Philosophical Transactions of the Royal Society B 344:83-90.

Bronstein, J. L. 1998. The contribution of ant-plant protection studies to our of mutualism understanding. Biotropica 30 : $150-161$.

Bronstein, J. L. 2015. Mutualism. Oxford University Press, Oxford, UK.

Caut, S., M. J. Jowers, X. Arnan, J. Pearce-Duvet, A. Rodrigo, X. Cerda, and R. R. Boulay. 2014. The effects of fire on ant trophic assemblage and sex allocation. Ecology and Evolution 4:35-49.

Chapman, C. A., and L. J. Chapman. 2003. Fragmentation and alteration of seed dispersal processes: an initial evaluation of dung beetles, seed fate, and seedling diversity. Biotropica 35:382-393.

Christian, C. E. 2001. Consequences of a biological invasion reveal the importance of mutualism for plant communities. Nature 413:635-639.

Collins, S. L., and M. D. Smith. 2006. Scale-dependent interaction of fire and grazing on community heterogeneity in tallgrass prairie. Ecology 87:2058-2067.

Cromsigt, J. P. G. M., and H. Olff. 2006. Resource partitioning and savanna grazers mediated by local heterogeneity: an experimental approach. Ecology 87:1532-1541.

de Dantas, V. L., M. Hirota, R. S. Oliveira, and J. G. Pausas. 2016. Disturbance maintains alternative biome states. Ecology Letters 19:12-19.

Dirzo, R., H. S. Young, M. Galetti, G. Ceballos, N. J. B. Isaac, and B. Collen. 2014. Defaunation in the Anthropocene. Science 345:401-406.

Estes, J. A., et al. 2011. Trophic downgrading of planet Earth. Science 333:301-306.

Fuhlendorf, S. D., and D. M. Engle. 2004. Application of the fire-grazing interaction to restore a shifting mosaic on tallgrass prairie. Journal of Applied Ecology 41:604-614.

Goheen, J. R., and T. M. Palmer. 2010. Defensive plant-ants stabilize megaherbivore-driven landscape change in an African savanna. Current Biology 20:1768-1772.

González-Teuber, M., J. C. Silva Bueno, M. Heil, and W. Boland. 2012. Increased host investment in extrafloral nec$\operatorname{tar}(\mathrm{EFN})$ improves the efficiency of a mutualistic defensive service. PLoS ONE 7:e46598.
Gray, M. A., S. L. Baldauf, P. J. Mayhew, and J. K. Hill. 2007. The response of avian feeding guilds to tropical forest disturbance. Conservation Biology 21:133-141.

Heady, H. F. 1960. Range Management in East Africa. Kenya Department of Agriculture. Government Printer, Kenya, Nairobi.

Holdo, R. M., R. D. Holt, and J. M. Fryxell. 2009. Grazers, browsers, and fire influence the extent and spatial pattern of tree cover in the Serengeti. Ecological Applications 19:95-109.

Jaffe, K. E., and L. A. Isbell. 2009. After the fire: benefits of reduced ground cover for vervet monkeys (Cercopithecus aethiops). American Journal of Primatology 71:252-260.

Keeley, J. E., W. J. Bond, R. A. Bradstock, J. G. Pausas, and P. W. Rundel. 2012. Fire in Mediterranean ecosystems: ecology, evolution and management. Cambridge University Press, New York, New York, USA.

Kerby, J. D., S. D. Fuhlendorf, and D. M. Engle. 2007. Landscape heterogeneity and fire behavior: scale-dependent feedback between fire and grazing processes. Landscape Ecology 22:507-516.

Kimuyu, D. K., R. L. Sensenig, C. Riginos, K. E. Veblen, and T. P. Young. 2014. Native and domestic browsers and grazers reduce fuels, fire temperatures, and acacia-ant mortality in an African savanna. Ecological Applications 24:741-749.

Klein, A.-M., B. E. Vaissière, J. H. Cane, I. Steffan-Dewenter, S. A. Cunningham, C. Kremen, and T. Tscharntke. 2007. Importance of pollinators in changing landscapes for world crops. Proceedings of the Royal Society B 274:303-313.

Kuria, S. K., and M. H. Villet. 2012. The role of ants and mammalian herbivores on the structure and composition of insect communities found on canopies of Acacia drepanolobium. African Journal of Agricultural Research 7:5317-5331.

Lars-Ove, W. 1997. Effects of forest fire and the ecology of fireadapted insects. Swedish University of Agricultural Sciences, Ultuna, Uppsala, Sweden.

Levick, S. R., G. P. Asner, T. Kennedy-Bowdoin, and D. E. Knapp. 2009. The relative influence of fire and herbivory on savanna three-dimensional vegetation structure. Biological Conservation 142:1693-1700.

Madden, D., and T. P. Young. 1992. Symbiotic ants as an alternative defense against giraffe herbivory in spinescent Acacia drepanolobium. Oecologia 91:235-238.

New, T. R.. 2014. Insects, fire and conservation. First. Springer, Cham, Switzerland.

Okello, B. D., T. P. Young, C. Riginos, D. Kelly, and T. G. O'Connor. 2008. Short-term survival and long-term mortality of Acacia drepanolobium after a controlled burn. African Journal of Ecology 46:395-401.

Palmer, T. M. 2004. Wars of attrition: colony size determines competitive outcomes in a guild of African acacia ants. Animal Behaviour 68:993-1004.

Palmer, T. M., T. P. Young, M. L. Stanton, and E. Wenk. 2000. Short-term dynamics of an acacia ant community in Laikipia, Kenya. Oecologia 123:425-435.

Palmer, T. M., T. P. Young, and M. L. Stanton. 2002. Burning bridges: Priority effects and the persistence of a competitively subordinate acacia-ant in Laikipia, Kenya. Oecologia 133: 372-379.

Palmer, T. M., M. L. Stanton, T. P. Young, J. R. Goheen, R. M. Pringle, and R. Karban. 2008a. Putting Ant-acacia mutualisms to fire. Science Letters to Editor 319:1759-1761.

Palmer, T. M., M. L. Stanton, T. P. Young, J. R. Goheen, R. M. Pringle, and R. Karban. 2008b. Breakdown of an ant-plant mutualism follows the loss of large herbivores from an African savanna. Science 319:192-195.

Palmer, T. M., D. F. Doak, M. L. Stanton, J. L. Bronstein, E. T. Kiers, T. P. Young, J. R. Goheen, and R. M. Pringle. 2010. 
Synergy of multiple partners, including freeloaders, increases host fitness in a multispecies mutualism. Proceedings of the National Academy of Sciences USA 107:17234-17239.

Piovia-Scott, J. 2011. The effect of disturbance on an ant-plant mutualism. Oecologia 166:411-420.

Pires, L. P., and K. Del-Claro. 2014. Variation in the outcomes of an ant-plant system: fire and leaf fungus infection reduce benefits to plants with extrafloral nectaries. Journal of Insect Science (Online) 14:84.

Pringle, E. G., R. Dirzo, and D. M. Gordon. 2012. Plant defense, herbivory, and the growth of Cordia alliodora trees and their symbiotic Azteca ant colonies. Oecologia 170:677-685.

Pringle, E. G., E. Akçay, T. K. Raab, R. Dirzo, and D. M. Gordon. 2013. Water stress strengthens mutualism among ants, trees, and scale insects. PLoS Biology 11:e1001705.

Pringle, R. M., D. M. Kimuyu, R. L. Sensenig, T. M. Palmer, C. Riginos, K. E. Veblen, and T. P. Young. 2015. Synergistic effects of fire and elephants on arboreal animals in an African savanna. Journal of Animal Ecology 84:1637-1645.

Quintero, C., K. E. Barton, and K. Boege. 2013. The ontogeny of plant indirect defenses. Perspectives in Plant Ecology, Evolution and Systematics 15:245-254.

Riginos, C., M. A. Karande, D. I. Rubenstein, and T. M. Palmer. 2015. Disruption of a protective ant-plant mutualism by an invasive ant increases elephant damage to savanna trees. Ecology 96:654-661.

Rodríguez-Cabal, M. A., M. A. Aizen, and A. J. Novaro. 2007. Habitat fragmentation disrupts a plant-disperser mutualism in the temperate forest of South America. Biological Conservation 139:195-202.

Ruiz Guajardo, J. C., D. Grossenbacher, R. Grosberg, T. M. Palmer, and M. L. Stanton. 2017. Impacts of worker density in colony-level aggression, expansion, and survival of the acacia-ant Crematogaster mimosae. Ecological Monographs https://doi.org/10.1002/ecm.1245

Sankaran, M., J. Ratnam, and N. Hanan. 2008. Woody cover in African savannas: the role of resources, fire and herbivory. Global Ecology and Biogeography 17:236-245.

Schumer, M., R. Birger, C. Tantipathananandh, J. Aurisano, M. Maggioni, and P. Mwangi. 2013. Infestation by a common parasite is correlated with ant symbiont identity in a plantant mutualism. Biotropica 45:276-279.

Schütz, S., B. Weissbecker, H. E. Hummel, K.-H. Apel, H. Schmitz, and H. Bleckmann. 1999. Insect antenna as a smoke detector. Nature 398:298-299.

Sensenig, R. L., M. W. Demment, and E. A. Laca. 2010. Allometric scaling predicts preferences for burned patches in a guild of East African grazers. Ecology 91:2898-2907.
Shannon, G., M. Thaker, A. T. Vanak, B. R. Page, R. Grant, and R. Slotow. 2011. Relative impacts of elephant and fire on large trees in a savanna ecosystem. Ecosystems 14:1372-1381.

Stachowicz, J. J. 2001. The structure of ecological communities. BioScience 51:235-246.

Stanton, M. L., and T. M. Palmer. 2011. The high cost of mutualism: effects of four species of East African ant symbionts on their myrmecophyte host tree. Ecology 92:1073-1082.

Stanton, M., T. M. Palmer, T. P. Young, A. Evans, and M. L. Turner. 1999. Sterilization and canopy modification of a swollen thorn acacia tree by a plant-ant. Nature 401:578-581.

Stanton, M. L., T. P. Palmer, and T. P. Young. 2002. Competition-colonization trade-offs in a guild of African acacia-ants. Ecological Monographs 72:347-363.

Staver, A., W. Bond, W. Stock, S. Van Rensburg, and M. Waldram. 2009. Browsing and fire interact to suppress tree density in an African savanna. Ecological Applications 19:1909-1919.

Stein, A., K. Gerstner, and H. Kreft. 2014. Environmental heterogeneity as a universal driver of species richness across taxa, biomes and spatial scales. Ecology Letters 17:866-880.

Thom, M. D., J. C. Daniels, L. N. Kobziar, and J. R. Colburn. 2015. Can butterflies evade fire? Pupa location and heat tolerance in fire prone habitats of Florida. PLoS ONE 10:1-22.

Trollope, W. S. W. 2011. Personal perspectives on commercial versus communal African fire paradigms when using fire to manage rangelands for domestic livestock and wildlife in Southern and East African ecosystems. Fire Ecology 7: $57-73$.

Verble-Pearsons, R. M., and S. P. Yanoviak. 2014. Effects of fire intensity on litter arthropod communities in Ozark oak forests, Arkansas, U.S.A. American Midland Naturalist 172: $14-24$.

Wardle, D. A., R. D. Bardgett, J. N. Klironomos, H. Setälä, W. H. van der Putten, and D. H. Wall. 2004. Ecological linkages between aboveground and belowground biota. Science 304:1629-1633.

Young, T. P., C. H. Stubblefield, and L. A. Isbell. 1997. Ants on swollen-thorn acacias: species coexistence in a simple system. Oecologia 109:98-107.

Young, T. P., B. Okello, D. Kinyua, and T. M. Palmer. 1998. KLEE: a long-term multi-species herbivore exclusion experiment in Laikipia, Kenya. African Journal of Range and Forage Science 104:92-104.

Zelikova, T. J., and M. D. Breed. 2008. Effects of habitat disturbance on ant community composition and seed dispersal by ants in a tropical dry forest in Costa Rica. Journal of Tropical Ecology 24:309-316.

\section{SUPPORTING INFORMATION}

Additional supporting information may be found in the online version of this article at http://onlinelibrary.wiley.com/doi/ 10.1002/ecy.1797/suppinfo 